relevant issues with respect to the quality of the plasma. All donors, irrespective of the type of compensation, undergo equivalent intensive screening and testing to eliminate the potential for transmitting disease. To improve the quality of plasma emphasis should be placed on educating donors and on screening programmes in addition to proper testing.

Secondly, plasma, whether from paid or unpaid donors, is subjected to validated fractionation and treatment processes, which result in viral partitioning and inactivation. The processes all have a demonstrated margin of safety.

Thirdly, self sufficiency is neither easy nor inexpensive to achieve. Two ways to increase the amount of products available are to decrease the amounts used (and thus the plasma required) or to increase the volumes of plasma collected as whole blood and plasma. It is not acceptable to lower the quality of treatment by decreasing the amount of factor VIII used by each haemophiliac patient. Two units of factor VIII per head of total population is estimated to provide basic care of haemophiliac patients but is not sufficient for all their needs, including treating spontaneous bleeding, elective and emergency surgery, and prophylaxis. It does not approach the objective of restoring haemophiliac patients to as near normal activity as possible (three units of factor VIII per head of population). This level of use would raise plasma needs by $50 \%$. The only realistic alternative in moving towards self sufficiency is to increase the collection of plasma. Plasmapheresis is the most practical means to accomplish this. This would require increased recruitment of donors and alteration of the regulations and some form of incentive to allow more frequent plasma donations. Further costs would be incurred as additional plasmapheresis centres would be needed.

Fourthly, doctors treating haemophiliac patients are concerned that the choice of product may come to depend more on price than quality. Extending the supply by making products of lower quality is not acceptable. The criteria for selecting products should include safety, efficacy, and availability in addition to cost. Higher purity can be achieved but at the sacrifice of the yield of factor VIII per litre of plasma, thus requiring larger volumes of plasma.

Fifthly, there does not seem to be any difference in the transmission of non-A, non-B hepatitis in the United Kingdom by intravenous immunoglobulins prepared from unpaid donors ${ }^{23}$ and by products from other countries that use remunerated donors. $^{45}$

In summary, paid donors do not necessarily equate with a higher risk of transmission of disease. More sophisticated testing of donors and manufacturing methods designed to inactivate any virus that may have escaped detection and entered the pool are being used. Moving towards self sufficiency without a defined programme for increasing the product supply could place a number of patients in jeopardy. The continued importation of products from non-European Community sources that has been determined to be safe and effective is the only logical solution until a long term programme for increased local supply of plasma and plasma products is in place.

ELIAS L GREENE

R ROUSELL

S BHONSLE

C BETANCOURT C MOORE

Cutter Biological, Miles Incorporated

PO Box 1986, Berkeley,

California 94701, USA

1 Cash JD. Supply of blood products. BMJ 1991;302:849. (6 April.)

2 Lever AML, Webster ADB, Brown D, Thomas HC. Non-A non-B hepatitis occurring in agammaglobulinaemic patients non-B hepatitis occurring in agammaglobulinaemic patient
after intravenous immunoglobulin. Lancet 1986;i: 1062-4.

3 Williams PE, Yap PL, Gillon J, Crawford RJ, Urbaniak SJ, Galea

G. Transmission of non-A, non-B hepatitis by $\mathrm{pH} 4$-treated G. Transmission of non-A, non-B hepatitis by pH4-
intravenous immunoglobulin. Vox Sang 1989;57:15-8.

4 Och's HD, Fischer SH, Virant FS, Lee ML, Kingdon HS, Wedgwood RJ. Non-A non-B hepatitis and intravenous immunoglobulin. Lancet 1985;i:404-5.
5 Bjoerkander J, Cunningham-Rundles C, Ludin P, Olsson R, Soederstroem R, Hanson LA. Intravenous immunoglobuli prophylaxis causing liver damage in 16 of 77 patients with hypogammaglobulinemia or $\operatorname{IgG}$ subclass deficiency. $\mathrm{Am} f$ Med 1988;84:107-11.

SIR, - Recent correspondence indicates that our concerns about the future of the blood transfusion service, and particularly the ready availability of freely given blood, are now being echoed publicly by professionals working with the service. ${ }^{1+4}$ We welcome the open discussion which replaces the caution and scepticism that initially greeted predictions made by the National Association of Blood Donors. It may still be considered inappropriate for donors to take an interest in the long term health of the service, but our independent views can make a valuable contribution to the discussion.

The recent European Community directive endorses the goal of self sufficiency in blood components obtained from voluntary unpaid donors. ${ }^{5}$ The economic case for paid blood donation' was prudently confined to the plasma protein concentrates from which bloodborne viruses can be eliminated. Even then, the cited research was from the United States. In the United Kingdom recipients of fresh blood components (for which sterilising procedures are not always possible) can rely not only on the potentially fallible screening of our blood but also on the health and experience of the National Blood Transfusion Service's regular donors, who have no pecuniary interest in offering their gift.

Blood donors have frequently been invoked, ${ }^{2+}$ yet have rarely been consulted. We wonder why this should be. In Scotland good mechanisms for information, consultation, and consent between the blood services and their donors have existed for many years. In France a tradition of robust debate between the transfusion service and an independen association of its donors has evolved into a fierce defence of the national blood programme with, it must be said, the committed support of the French government. In England and Wales, too, such opportunities now exist but are viewed with caution.

Any view that donors are "partners" in the service only when rhetoric or shortage demands gravely underestimates our potential to defend both our gift to the community and the community's interest in one of the few remaining vital communal services. Last year, our association noted several contradictions and potential drawbacks in the new NHS policy for the transfusion service and asked about the security of national policy and investment planning. In response we were swiftly, categorically, and publicly reassured that no needy patient would go without a blood transfusion, whatever the financial arrangements happened to be. This positive reaction to the concerns of an independent donors' association may encourage all blood donors in England and Wales, and those who also collect and prescribe blood components, to join the National Association of Blood Donors in its strengthening of the National Blood Transfusion Service at a crucia time. In this way the association's founding principles may be protected.

P A FELDMAN $\begin{array}{r}\text { C KEANEY } \\ \text { J WINKELMAN }\end{array}$

National Association of Blood Donors,

Headington, Oxford OX3 9HT

1 Cash JD. Supply of blood products. BMF 1991;302:849. (6 April.)

Contreras M. Supply of blood products. BMF 1991;302:1019. (27 April.)

Christie RB. Supply of blood products. BMJ 1991;302:1019. (27 April.)

4 Ala FA, Fraser ID. Supply of blood products. BMY 1991;302 1148. (11 May.)

5 Council directive of 14 June 1989. Official fournal of the European

Communities 1989 June 28:No L181.44-6. (89/381/EEC.)

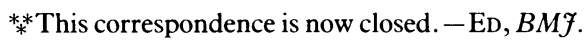

\section{Deaths of patients waiting for coronary surgery}

SIR,-It comes as no surprise that Dr Michael Marber and colleagues found waiting times for coronary angiography and surgery to be longer in the NHS than in the private sector.' What is remarkable is that despite long NHS waiting lists for surgery only nine patients died from cardiac causes over the 10 years of the study. This figure could be more meaningfully interpreted, however if the actual number on the NHS surgical lists was reported.

An audit of 92 patients added to our waiting list for elective surgery in 1988 showed no deaths during a median wait of 93 days (range 8-400). This was despite an incidence of left main stem stenosis of $17 \%$ and of three vessel disease of $84 \%$. Furthermore, $40 \%$ had impaired left ventricular function. Dr Marber and colleagues were disturbed to note that eight of their nine patients who died while awaiting surgery had three vessel disease and left ventricular dysfunction. We do not, however, have the benefit of perspective as they did not state how many of their patients with such a combination came to no harm while waiting.

I agree that these patients merit priority for surgery, but when such advanced and high risk disease is so common triage becomes difficult. In our experience conventional exercise electrocardiography makes no major contribution to triage because it nearly always yields positive results in our patients requiring surgery -indeed, many are selected for angiography in the first place partly because of a prognostically worrying exercise test result. Perhaps performing such exercise testing with the patients still taking their regular antianginal treatments (as opposed to stopping them temporarily for the test) might refine the process of triage ${ }^{4}$ as a result that is abnormal despite treatment implies inadequate "cardioprotection" and thus continuing vulnerability while the patient is on the waiting list.

The real issues raised by Dr Marber and colleagues remain unresolved: Can there be consensus about what constitutes dangerous and therefore unacceptable delay? If so can NHS waiting times be shortened? If not can triage be improved in a cost effective way?

Department of Cardiology,

St Bartholomew's Hospital,

London ECIA 7BE

1 Marber M, MacRae C, Joy M. Delay to invasive investigation and revascularisation for coronary heart disease in South West Thames region: a two tier system? BMF 1991:302:1189-91. Thames

$2 \mathrm{Lim}$ R, Kreidieh I, Dymond DS, et al. Is the waiting list a safe place for outpatients awaiting coronary bypass surgery? Health Trends (in press).

3 Naylor CD, Baigrie RS, Goldman BS, Basinski A. Assessment of priority for coronary revascularisation procedures. Lancel 1990;335:1070-3.

4 Lim R, Dyke L, Dymond DS. Prognostic importance of failure of medical therapy to normalise exercise ejection fraction response in coronary artery disease. $\mathcal{F}$ Am Coll Cardio 1991;17:183A

\section{The cyclotron saga continues}

SIR, - The trial of high energy neutrons in the management of pelvic cancers at Clatterbridge Hospital reported by $\mathrm{Dr} R \mathrm{D}$ Errington and colleagues $^{1}$ was so poorly designed that, in the best of circumstances, it could not have shown an advantage for either conventional photons or neutron treatment in advanced disease. The study combined a relatively small number of patients with four very different cancers, some of whom must have entered the study with distant metastases, making the end point of one year survival totally meaningless. The title of the paper, which says that the study was stopped because of increased 
mortality, is deliberately misleading: the excess deaths were due to distant metastases. These deaths were inevitable even before the patients entered the flawed trial. We know that this was the basis for the rejection of the study as totally inappropriate by the Radiation Therapy Oncology Group's fast neutron group in the US. So why waste time, precious resources, and the trust of patients?

Yet Dr Errington and colleagues have persevered and delivered another antineutron headline. Such a headline might have been critical to the project to get a cyclotron where it would be used effectively for the benefit of patients. But this had already been torpedoed - after a brilliant, well orchestrated campaign - by the withdrawal of what has been represented as the infamous Thatcher $£ 6$ million repayable loan-which was not a grant for cancer research, as is so often misreported, but a repayable loan for treatment.

Happily, one important message that can be gleaned from this study is the absence of excess normal tissue morbidity in the pelvis of patients treated with $19 \cdot 2$ Gy of high energy neutrons in 12 fractions over 28 davs. Further studies - sadly, probably elsewhere-will identify the true role for neutrons in treating advanced cancer.

THELMA BATES

South East London Radiotherapy Centre.

St Themas's Hospital,

London SE: $7 \mathrm{EH}$

1 Errington RD, Ashby D, Gore SM, Abrams KR, Mvint Bonnett DE, el al. High energy neutron treatment for pelvic Bonnett DE, et al. High energy neutron treatment for pelsic 1991:302:1045-51. 4 May

AUTHORS' REPLy, - Dr Bates's comments are inappropriate as far as the detail of the design and subsequent analysis of the Clatterbridge trial of high energy neutrons versus photons in advanced pelvic cancers are concerned.' The trial featured informed consent, no exclusions from analysis, randomisation from the first patient, and the same investigations and follow up procedures for patients treated with neutrons and photons. It lacked power to detect moderate benefit for high energy neutrons from the point of view (that is, equipoise) reflected in the prior opinion of peers - a problem common to all trials of neutrons because of the cost of cyclotrons and need for all patients to be assessed by the same doctors. There was, however, no lack of power to exclude modest benefit for high energy neutrons from the prior position reflected in the results of trials of low energy neutrons. A priori, peer opinion moderated pessimism about low energy neutrons. A posteriori, the relevance of the results obtained with low energy neutrons had to be reassessed.

Randomisation should preclude imbalance of patients with occult metastases between neutron and photon treatment. It will not do so in every trial. The issue of fortuitous imbalance is addressed by retrospective proportional hazards adjustment of major prognostic factors ascertained before randomisation and themselves related to metastatic risk. Retrospective adjustment should not be made for metastatic state as ascertained after randomisation because the ascertainment process or the metastases, or both, could be related to treatment. With respect to the data on morbidity, Dr Bates has overlooked the caution we advocated in their interpretation because of the small number of patients at risk of developing later severe reactions.

The statement concerning the rejection of our study by colleagues in the Radiation Therapy Oncology Group is misleading.' 'The paper was presented at meetings of the group's Neutron Collaborative Working Group in the US in March and October 1990 and March 1991. At no time did the working group question the merits of our trial or reject its findings. At the time that the cyclotron controversy started ${ }^{2}$ the studies at Clatterbridge were still recruiting patients. This continued despite the difficulties caused by the extreme views expressed by the protagonists and antagonists of neutron treatment. These certainly were a betraya of the trust of patients and restricted the use of a precious resource primarily carrying out objective clinical research.

As far as other studies are concerned, the cyclotron at Clatterbridge has been a major contributor to the Radiation Therapy Oncology Group and Medical Research Council neutron head and neck trial (data validated by a site visit by the Radiation Therapy Oncology Group in November 1990). The role of neutrons in locally advanced salivary gland ${ }^{3}$ and air sinus tumours ${ }^{+}$is acknowledged, with treatment available at Clatterbridge since July 1987. Alternative approaches to trials of neutron treatment have been suggested. Unti these can be put into practice the results of randomised studies and their objective appraisal are a more appropriate guide to the correct application of neutron treatment than clinical anecdotes and subjective views, which have been such a feature of the cyclotron saga.

R D ERRINGTON

D ASHBY

S M GORE

Mersey Regional Centre for Radiotherapy

and Oncology

Clatterbridge Hospital

Bebington,

Merserside L $63+\mathrm{JY}$

Errington RD, Ashby D, Gore SM. Abrams KR, Mvint S, Bonnett D, et al. High energy neutron treatment for pelvic cancers: study stopped because of increased mortality, $B M$ 1991;302:1045-51. (4 May.)

2 Smith R. Radiotherapy's second setback. Promotion of a potentially dangerous treatment by a backdoor decision. $B M$ $1988 ; 297: 1625-6$

3 Griffin TW, Pajak TF, Laramore GE, Duncan W, Richter MP, Hendrickson FR, et al. Neutron vs photon irradiation of inoperable salivary gland tumors: results of an RTOG-MRC cooperative randomized study. Int $\mathrm{f}$ Radiat Oncol Biol Phys 1988:15:1085-90.

4 Errington RD Advanced carcinoma of the paranasal sinuses treated with $7.5 \mathrm{MeV}$ fast neutrons. Bull Cancer 1986:73: $569-76$

5 Withers HR. Neutrons and other clinical trials: impossible dreams? Int f Radiat Oncol Biol Phys 1987;13:1967-70.

6 Parker RG An appraisal of particle radiation therapy research. Int F Radiut Oncol Biol Phys 1988;15:1+35-9.

\section{What determines the age at the menopause?}

SIR, - Though I agree with Dr Jean Ginsberg that parity, race, and smoking are factors that influence the age at the menopause, a link with nutrition is not clear cut.' Genetic and racial factors and high parity are probably the most important determinants. The connection may lie in "genetic programming," to which Dr Ginsberg refers. This causes some women to ovulate longer, which mav lead to higher parity and possibly a later menopause. It is difficult to understand why multiple pregnancy should lower the age at the menopause when there is a correlation between high parity and multiple pregnancy.

Viable pregnancy is rare in women beyond the age of 50 . This has been presumed to be a result of increasing anovulation. Nevertheless, Novak found a surprising number of women $-23 \%$ in his study of 200 women above 50 -showing histological evidence of recent ovulation. ${ }^{2}$ In a recent study (paper in preparation) of pregnancies in seven women confirmed as being aged over 50 conducted over two years at Dudley Road Hospital, Birmingham, some fascinating features emerged. Four are worthy of consideration.

Firstly, all the women were Asian. Four came from the Mirpur district of Pakistan and three from the Sylher district of Bangladesh. Both these regions are underdeveloped and overpopulated. Secondly, the average age at the time of the latest delivery was $52 \cdot 8$ years (oldest 59 , youngest 51 ). The age was checked from birth certificates or passports and cross checked with that on the birth certificate of the first child. Thirdly, all these women were highly parous with an average of $8 \cdot 8$ children. Two of the seven women had also delivered twins. Finally, the average age at the first pregnancy had been 31 . Every one of these women was a grandmother.

Such examples of ovulation continuing well beyond the average age of the menopause may indeed be due to genetic programming. As well as a late age at the menopause the effect of this is, more importantly, prolonged fertility well into the sixth decade. Understanding and perhaps regulating the factors determining the age at the menopause could have important effects in controlling fertility, particularly in already overpopulated countries.

H NARAYAN

Department of Obstetrics and Gynaecology,

University of Leicester.

Leicester Roval Infirmary,

PO) Box 65 ,

Leicester LE2 7LX
I (iinsburg J. What determines the age at the menopause? BMf 1991:302:1288-9. (1 June.)

2 Novak ER. Ovulation after fifty. Obstet Gynaecol 1970;36: 903-10

SIR,-In her editorial ${ }^{\prime}$ Dr Jean Ginsberg has omitted to mention that left handed women have earlier menopauses than right handed women. This association may be related to possible correlations between left handedness and autoimmune disorders, which may include reactions against hormone receptor sites and oocytes. ${ }^{2}$

JOHN MCGARRY

Barnstaple,

North Devon EX31 4HN

1 Ginsberg J. What determines the age at the menopause? BMf 1991;302:1288-9. (1 June.

2 Leidy LE. Early age at menopause among left handed women. Obstet Gynecol 1990;76:1111-4

\section{Increasing the uptake of cervical smear testing among Asian women}

SIR,-Dr Brian R McAvoy and Rabia Raza's recent article about the effectiveness of personal visits in increasing the uptake of cervical smear testing among Asian women' ${ }^{1}$ prompted a letter of response $^{2}$ that raised once again the issue of the availability of the target population for screening and the inaccuracy of recorded addresses in the databases of family health services authorities. We agree that studies to assess the effectiveness of efforts to promote screening are dogged by the problem of women not being resident at the address on the invitation and no access being possible at the address.

The discrepancies between the findings of $\mathrm{Dr}$ McAvoy and Rabia Raza and Drs Joyce M Carter and Susan E Ellerby with regard to the proportion of women who were contactable at the address on the screening invitation may be accounted for by the different populations that were being studied. Dr McAvoy and Rabia Raza visited randomly selected Asian women who had never been tested previously whereas Drs Carter and Ellerby visited any women who had not responded to the callrecall scheme for cervical cytology: $\mathrm{Dr}$ McAvoy and Rabia Raza found that 159 of 482 declined to participate or were not contactable whereas Drs Carter and Ellerby found that at 58-68\% of 1273 addresses no access was possible and $12-13 \%$ of addresses were incorrect.

In following up women who do not attend for 